\title{
O enfermeiro em face ao processo de morte do paciente pediátrico
}

\section{The nurse against the death process of the pediatric patient}

\author{
Flávia Fagundes Souza ${ }^{1}$ [D , Flávia Prazeres Reis ${ }^{2}$ (D) \\ 1. Discente do curso de Enfermagem pela Universidade Católica do Salvador (UCSal), Salvador, BA, Brasil. 2. Docente do curso de Enfermagem pela \\ Universidade Católica do Salvador (UCSal), Salvador, BA, Brasil
}

\section{Resumo}

Objetivo: conhecer os impactos vivenciados por enfermeiros no processo de morte do paciente pediátrico. Método: pesquisa de natureza qualitativa, descrita e exploratória, realizada em um hospital pediátrico na cidade de Salvador- BA, em abril de 2017. Foram entrevistados 10 enfermeiros atuantes em Pediatria há mais de dois anos. Da análise dos relatos coletados, depreenderam-se quatro categorias temáticas. Resultados: constatou-se que o enfrentamento da morte constitui uma situação complicada e dolorosa, e que a sua grande frequência nos hospitais não modifica os impactos sofridos por esses profissionais. Ficou evidente que o convívio desses enfermeiros com o paciente pediátrico favorece a criação de laços afetivos. Considerações finais: concluiu-se que a temática da morte ainda é pouco abordada na formação profissional, e que a criação de serviços de apoio psicológico nas instituições poderia contribuir bastante para minimizar os danos causados pelo enfrentamento em longo prazo com esses óbitos.

Palavras-chave: Enfermagem. Enfermagem Pediátrica. Morte. Impactos.

\begin{abstract}
Objective: to know the impacts experienced by nurses in the pediatric patient death process. Method: qualitative research, described and exploratory, performed in a pediatric hospital, in the city of Salvador, Bahia, in April, 2017. Ten nurses working in pediatrics were interviewed more than two years ago. From the analysis of the collected reports, four thematic categories were perceived. Results: it was concluded that coping with death is a complicated and painful situation, and that its high frequency in hospitals does not change the impact suffered by these professionals. It was evidenced that the interaction of these nurses with the pediatric patient favors the creation of affective bonds. Final considerations: it was concluded that the subject of death is still little approached in the professional formation and that the creation of psychological support services in the institutions could contribute a lot to minimize the damages caused by the long-term confrontation with these deaths.
\end{abstract}

Key words: Nurse. Pediatric. Death. Impacts.

\section{INTRODUÇÃO}

Atualmente, tem ocorrido uma discussão crescente sobre os impactos que uma internação hospitalar pode causar a um paciente pediátrico. Essa preocupação se dá pelo fato de a criança encontrar-se afastada da sua rotina, do ambiente familiar e da escola, ocorrendo, assim, a perda de suas referências. Dessa maneira, o paciente pediátrico passa a ser tratado como um membro da família de muitos funcionários da equipe multidisciplinar ${ }^{1}$.

De acordo com a Constituição Federal, Art. 227, o Estatuto da Criança e do Adolescente (ECA) e a Lei Federal (№ 8.069, de 13 de julho de 1990) em vigor no Brasil, é determinado que o atendimento às necessidades e aos direitos de crianças e adolescentes é "prioridade absoluta" das políticas públicas do País. No Art. 2o, o ECA considera "criança" a pessoa até 12 anos de idade incompletos; e "adolescente", aquela entre 12 e 18 anos de idade ${ }^{2}$.
A morte é uma etapa da vida, porém ainda, nos dias de hoje, é uma questão difícil de ser enfrentada e entendida, principalmente em países do Ocidente, onde a morte é pouco abordada pela sociedade, causando receio. Embora seja uma parte inevitável do ciclo biológico de todo ser humano cientificamente, lidar com o assunto ainda causa dor em muitas pessoas $^{3}$.

O término da vida na infância é considerado mais doloroso que na vida adulta, já que a morte de uma criança leva a um conceito de tragédia e interrupção do ciclo da vida. Dessa maneira, a sobrevida dela se constitui como um objetivo principal para equipe, devido à alta possibilidade de cura em pacientes pediátricos ${ }^{3}$.

Enfermeiros, docentes e acadêmicos de enfermagem vivenciam constantemente situações de morte na atuação prática. É 
possível visualizar inúmeras reações nos integrantes da equipe que atuam em setores ligados diretamente com a morte. Alguns se retraem, outros choram, questionam-se acerca do porquê da morte na finitude humana e criam mecanismos de defesa, como a racionalização do cuidar, tentando, assim, agir mecanicamente, sem estreitar os laços com esses pacientes ${ }^{4}$.

Pesquisas sobre os fatores que levavam ao estresse e a síndrome de Bournot em enfermeiros da área de pediatria detectaram: laços disseminados entre enfermeiros e pacientes; enfermagem extremamente envolvida com os pacientes e família, distante dos outros profissionais e baixa autoestima profissional. Sendo assim, o óbito do paciente refletia como uma derrota contra a morte e a recuperação uma vitória ${ }^{5}$.

Assim, considera-se este estudo significativo para a reflexão sobre a temática, compreender e acrescentar, na vivência desses profissionais, o processo de morte/morrer da clientela assistida, visto que muitos não conseguem lidar com o óbito de crianças sem sofrer, o que, em longo prazo, pode acarretar patologias.

Visando a um aperfeiçoamento na qualidade de vida e assistência prestada ao processo de morte e morrer, visto que o enfermeiro é um elemento chave e norteador na equipe multidisciplinar, este estudo teve como objetivos conhecer os impactos vivenciados por enfermeiros no processo de morte do paciente pediátrico.

\section{MÉTODOS}

Trata-se de um estudo de abordagem qualitativa do tipo descritivo-exploratório. O campo para coleta de dados foi um hospital pediátrico no estado da Bahia.

Para a inserção de participantes na pesquisa, seguiram-se critérios de inclusão e exclusão. Os critérios de inclusão foram: ter no mínimo dois anos de atuação em Pediatria, estar em exercício profissional no período da coleta e assinar o TCLE. Os critérios de exclusão foram: estar em férias ou não estar presente no dia da coleta de dados. Seguindo esses critérios, participaram do estudo dez enfermeiros. entrevista semiestruturada, dividida em duas etapas, aplicada individualmente e no local de trabalho dos participantes, com agendamento prévio, embora elas tenham sido gravadas com o consentimento dos participantes. As entrevistas tiveram média de duração de 10 minutos.

Na primeira etapa, foram questionados os dados de identificação dos participantes (pseudônimo, sexo, idade, religião, número de filhos, tempo de formado, tempo de serviço na área e data da última vivência do processo de morte da criança); e a segunda etapa por meio da questão norteadora: "como você vivencia o processo de morte pediátrico?"

As entrevistas foram transcritas na íntegra, corrigindo apenas erros gramaticais, quando necessário, sem alterar o sentido das frases e respeitando as diretrizes para pesquisas com seres humanos.

Os relatos coletados foram submetidos à análise de dados, modalidade temática e categorizados em: 1 - os impactos vivenciados por enfermeiros nesse processo; 2 - a influência desses impactos na qualidade de vida e a assistência desses profissionais; 3 - os vínculos afetivos criados entre o profissional e o paciente; e 4 - as estratégias utilizadas pelos enfermeiros para superar esses impactos.

Este estudo fundamenta-se na Resolução 466/12, do Conselho Nacional de Saúde, que regulamenta a pesquisa em seres humanos no país e foi aprovado pelo Comitê de Ética em Pesquisa da Universidade Católica do Salvador, com Parecer número 2.023.428/2017.

\section{RESULTADOS E DISCUSSÃO}

Os resultados serão apresentados em duas partes: a primeira refere-se ao perfil dos participantes do estudo, com os dados relativos a sexo, idade, religião, número de filhos, tempo de formação, tempo de atuação em pediatria e período da última vivência de um processo de morte no decorrer da assistência. A segunda parte são os dados obtidos por meio dos discursos referentes à vivência desses profissionais em face do processo de morte do paciente pediátrico.

Os dados foram coletados no mês de abril de 2017, por meio de

Quadro 1. Caracterizações sociodemográficas e ocupacionais dos enfermeiros. Salvador, Bahia, 2017.

\begin{tabular}{|c|c|c|c|c|c|c|c|}
\hline Pseudônimo & Sexo & Idade & Religião & № de filhos & $\begin{array}{l}\text { Tempo de } \\
\text { formação }\end{array}$ & $\begin{array}{l}\text { Tempo de atuação } \\
\text { (Pediatria) }\end{array}$ & $\begin{array}{l}\text { Última } \\
\text { vivência }\end{array}$ \\
\hline Diamante & Feminino & 25 & Católica & 0 & 2 anos e 6 meses. & 2 anos e 4 meses. & Há 1 ano. \\
\hline Rubi & Feminino & 27 & Católica & 0 & 2 anos e 6 meses. & 2 anos. & Há 1 mês. \\
\hline Esmeralda & Feminino & 26 & $\begin{array}{l}\text { Cristã } \\
\text { protestante }\end{array}$ & 0 & 2 anos e 2 meses. & 2 anos. & Há 1 mês. \\
\hline Turmalina & Feminino & 25 & Católica & 0 & 3 anos. & 2 anos e 9 meses. & Há 1 ano. \\
\hline Jade & Feminino & 25 & Não possui & 0 & 2 anos e 9 meses. & 2 anos e 6 meses. & Há 6 meses. \\
\hline Opala & Feminino & 27 & Espírita & 0 & 5 anos e 6 meses. & 5 anos. & Há 2 meses. \\
\hline
\end{tabular}




\begin{tabular}{lccccccc}
\hline Pseudônimo & Sexo & Idade & Religião & No de filhos & $\begin{array}{c}\text { Tempo de } \\
\text { formação }\end{array}$ & $\begin{array}{c}\text { Tempo de atuação } \\
\text { (Pediatria) }\end{array}$ & $\begin{array}{c}\text { Última } \\
\text { vivência }\end{array}$ \\
\hline Safira & Feminino & 27 & Espírita & 0 & 2 anos e 8 meses. & 2 anos e 6 meses. & Há 1 mês. \\
Turquesa & Feminino & 34 & Evangélica & 0 & 6 anos. & 5 anos e 6 meses. & Há 2 anos. \\
Ametista & Feminino & 35 & Espírita & 1 & 7 anos. & 7 anos. 1 mé 1 mês. \\
Ágata & Feminino & 33 & Católica & 0 & 10 anos. & 10 anos. Há 6 meses. \\
\hline
\end{tabular}

Analisando o quadro 1, verifica-se que $100 \%$ da amostra é do sexo feminino; a idade varia de 25 a 35 anos, obtendo uma média de idade de 28,4 anos. Em relação à religião - $40 \%$ referem ser católicas, $30 \%$ espíritas, $10 \%$ cristãs protestantes, $10 \%$ evangélicas e $10 \%$ não possuem religião. Número de filhos: apenas $10 \%$ são mães; o tempo de formação varia de dois anos e dois meses a dez anos, obtendo uma média de quatro anos e sete meses; o tempo de atuação em pediatria varia de dois a dez anos, obtendo uma média de quatro anos e dois meses, e a última vivência com um processo de morte varia de um mês a dois anos.

Os impactos vivenciados por enfermeiros no processo de morte do paciente pediátrico

Nos dias atuais, o principal local de ocorrência de morte é no hospital, o que ocasiona, no convívio rotineiro dos profissionais de saúde com essa realidade, um conflito por ter a responsabilidade de prestar cuidados ao paciente que se encontra em processo de morte e a vontade de propiciar a cura desse indivíduo, mesmo que seja impossível ${ }^{6}$.

Assim, o relato de vivência com processos de morte pediátrica apareceram em todos os discursos das entrevistadas; todas relataram como uma situação difícil de ser vivida e abordada. Embora tenham afirmado que, com o passar dos anos na profissão, a postura diante da morte tenha mudado, a dor ainda permanece com cada episódio.

Eu acho que o processo de morte é uma questão que a gente nunca vai se acostumar né? Por que embora a gente esteja dentro da realidade hospitalar, a gente nunca espera que a criança venha a óbito ou então a gente acha que nunca vai acontecer com a gente. No início eu achava que seria bem mais difícil né? Você contornar a situação, mas infelizmente com o tempo a gente começa saber lidar, eu não sei se isso é bom ou se isso é ruim né? (Diamante)

No primeiro óbito que eu "peguei", eu fiquei supernervosa, chorei muito, mas, depois que você começa a vivenciar vários óbitos, acaba por ser algo mesmo que faz parte da rotina da gente, entendeu? (Turmalina)

A princípio era muito complicado aceitar porque é criança, e a gente geralmente acha que tem uma vida pela frente, não que algo justifique a morte de um adulto ou idoso, mas, na pediatria, a gente acaba internalizando que o paciente tem uma vida toda pela frente, [...] é como se fosse uma vida ceifada né? Interrompeu um processo que tinha um longo ciclo ainda pela frente. A minha religião me ajudou muito a entender o que acontece aqui no hospital, mas não foi fácil [...] pra mim foi muito difícil, hoje ainda é. (Safira)

Na realidade, eu acho que o impacto é mais essa sensação de impotência que a gente sente, a maioria das mortes que eu vivenciei era paciente já em cuidados paliativos, então a gente acaba enfrentando de uma maneira melhor, já que, teoricamente, era algo esperado [...] querendo ou não, mexe com as nossas emoções. (Esmeralda)

Entende-se que, no que se refere a lidar com a morte pediátrica, apesar do convívio constante em seu dia a dia, as enfermeiras entrevistadas compartilharam dos mesmos discursos, demonstrando que, apesar da dificuldade, em longo prazo, torna-se mais aceitável, porém não menos doloroso

A morte, apesar de inevitável em alguma fase da vida de um indivíduo, não é uma questão simples de ser abordada, sobretudo pelo fato de que nossa cultura, ainda hoje, é caracterizada pelo medo e não pela aceitação do fato. 7

Eu sinto uma tristeza, uma frustração, angústia, tantos sentimentos, luto mesmo [...] A gente precisa entender o nosso papel, mas, independente disso, quando vemos uma criança, pensamos que ainda tem um futuro pela frente. (Ametista)

É muito complicado, eu absorvo muito, eu choro muito em casa, fico bem pra baixo. Eu escolhi trabalhar com pediatria, mas a parte da morte é bem difícil. (Rub

A última situação que eu vivenciei [...] o paciente veio a óbito, e já tinha sete anos de casa e eu era amiga dele, através da instituição, criei um laço afetivo com a família, conheci a família, já tinha ido pra aniversário [...] e fiquei muito mal no dia do óbito, chorei bastante, me liberaram pra ir pra casa, não tive condições de permanecer no turno do trabalho. (Diamante)

Esses achados se assemelham com o que foi proposto em outros estudos, em que os autores relatam que os enfermeiros apresentam sentimentos negativos quando vivenciam o óbito em crianças.

Especificamente na pediatria, esse impacto costuma ser maior. Lidar com a morte por si só é uma questão difícil, mas a sua ocorrência em uma fase precoce, ou seja, nos primeiros anos de vida de uma pessoa, implica dificuldades de compreensão e aceitação. Estudos comprovam que os enfermeiros de UTI pediátrica sofrem mais com o processo de morte, pois entendem que a vida da criança foi interrompida e que fracassou por não conseguir evitar a ocorrência do óbito ${ }^{4}$.

A dor da perda em relação a uma criança é muito maior quando comparada a um idoso. Quando uma morte pediátrica acontece sempre surge o questionamento: por que aconteceu com a criança que ainda tinha toda uma vida pela frente? Esse questionamento tende a despertar os sentimentos de negação, de impotência, de perda, de tristeza nos profissionais de enfermagem e em todos os familiares ${ }^{8}$. 
Pode-se notar que a maior angústia manifestada pelos profissionais entrevistados quase sempre estava relacionada ao fato de a criança ainda estar no início da vida e, por causa de uma patologia, não conseguir completar o seu ciclo e realizar sonhos como: formatura, casamento, filhos, entre outros.

Torna-se evidente a dificuldade desses profissionais em lidar com a morte de seus pacientes pediátricos. Em muitos relatos, ficou clara a caracterização da dor quando a palavra morte era pronunciada e relacionada a algum episódio que acontecera em seu exercício profissional. Ainda sob essa ótica, foi analisado o grau de influência que esses impactos possuem sobre a qualidade de vida e a assistência dessas enfermeiras.

\section{A influência desses impactos na qualidade de vida e assistência desses profissionais}

Embora estejam sofrendo, os profissionais de enfermagem, no exercício de suas funções, são obrigados a continuar cuidando do outro. Com o intuito de realizar seu trabalho, sem adoecer, esses indivíduos precisam desenvolver mecanismos para lidar com os impactos gerados em face do contato com o sofrimento do outro ${ }^{6}$.

Assistir constantemente o óbito em pacientes pediátricos e por, muitas vezes, vivenciar situações que permeiam dor, sofrimento, angústia e não aceitação por parte dos pacientes e de seus familiares fazem que o enfermeiro, como ser humano dotado de sentimentos como qualquer outro, possa transferir todos esses sentimentos negativos para o seu dia a dia e ter dificuldade em diferenciar o pessoal do profissional.

É complicado, sim, a gente realmente acaba levando pro pessoal, inclusive já tive colegas que até desistiram de trabalhar com pediatria. (Ametista)

No início da minha carreira, influenciou muito na minha qualidade de vida, por exemplo, a primeira morte que eu vi, eu não queria mais entrar na UTI, eu não queria mais ser enfermeira, eu não queria mais voltar pro hospital, eu achei que era a pior coisa que eu poderia ver na vida, dormia e sonhava, tinha pesadelo, pensava na criança o tempo inteiro, então me atrapalhou muito. (Ágata)

Vida influencia sim, assistência não. Vida sim por que eu acabo levando pra casa, eu acabo levando esse sentimento por que às vezes a gente quer resolver tudo e a gente não consegue (pausa para o choro), não tem como falar, tende a melhorar, por que a falta de experiência no início complica. (Opala)

Nota-se que esses impactos influenciam na qualidade de vida desses profissionais, pois, para eles, não é fácil deixar todos esses sentimentos apenas no trabalho. Em muitos relatos, percebe-se que os pensamentos negativos costumam aparecer quando o profissional já está em casa, demonstrando, assim, a dificuldade em desvincular-se dos episódios vivenciados.

Inúmeros estudos confirmam que enfermeiros, por lidarem frequentemente com a dor, o sofrimento, a angústia, a perda, o stress e a morte, sofrem impactos devastadores em sua capacidade relacional, racional e emocional. Com o intuito de compreender o outro, o enfermeiro pode ser invadido pelos sentimentos e problemas do paciente e de sua família. Como exemplo, têm-se os casos de enfermeiros que desenvolveram uma "depressão por empatia" 9 .

Quanto à influência na assistência prestada após episódios de óbitos, as enfermeiras entrevistadas foram unânimes em suas respostas.

Não influencia não, consigo continuar meu plantão normal, afinal temos que lutar por outras vidas. (Turmalina)

$\mathrm{Na}$ assistência não, por que enquanto existe vida, a gente quer doar o melhor de si, para que não chegue nesse último processo, que é o processo da morte. (Safira)

Vai ter influência no pessoal, sim, a gente vai ficar meio deprimida, mas não deixo que isso interfira na assistência para os outros pacientes, para outras crianças no caso. (Jade)

[...] Querendo ou não, mexe um pouco com as nossas emoções, até o momento nas situações que eu vivi, eu consegui levar minha rotina de trabalho normal. (Esmeralda)

Analisando os achados, pode-se afirmar que esses impactos têm influência significativa na qualidade de vida desses profissionais, porém não interferem na qualidade de sua assistência. Quando esses achados foram relacionados com algumas literaturas, trouxeram divergência nas informações.

Os enfermeiros buscam superar esses impactos no cotidiano assistencial e pessoal; para isso, buscam estratégias para desvincular a relação pessoal do profissional. Relatos afirmam que existe a tentativa de aprender a lidar com o sofrimento e a angústia vivida pelos familiares, porém, na maioria das vezes, a tentativa é frustrada e acarreta em abalos na assistência ${ }^{10}$.

Os enfermeiros criam mecanismos de defesa para evitar o sofrimento, porém podem acabar criando uma armadura e, consequentemente, um distanciamento do paciente, o que se manifesta como uma aparente frieza e insensibilidade humana. Isso pode influenciar negativamente no crescimento profissional e pessoal do indivíduo, interferindo em sua maneira de prestar os cuidados ao paciente em finitude de vida ${ }^{4}$.

Os enfermeiros entrevistados nesta pesquisa afirmaram, em seus relatos, que os impactos tornavam-se mais fortes quando o óbito era de uma criança, com a qual eles possuíam uma maior proximidade. Dessa maneira, foram analisados, também, os vínculos afetivos criados entre o profissional e o paciente pediátrico.

\section{Os vínculos afetivos criados entre o profissional e o paciente}

A enfermagem é uma profissão que tem como foco o cuidar e que interage com o ser humano em todas as etapas de sua vida, do nascimento até a morte; é quem permanece mais tempo próximo ao paciente em sua internação, pois seu trabalho não se restringe somente aos procedimentos técnicos, engloba, também, diversas especialidades, para assistir o paciente por completo. Por ter uma proximidade com um cliente em iminência de morte, corre-se o risco da criação de laços e 
$\operatorname{afetivos}^{11}$.

A enfermagem, na maioria das vezes, é quem está presente nos momentos difíceis vivenciados pelos pacientes e familiares, é quem eles buscam quando necessitam de ajuda ou esclarecimento de suas dúvidas, o que aumenta a convivência entre profissional e paciente ${ }^{12}$.

Quando o cuidado é prestado a pacientes nessa faixa etária, a facilidade de criação de vínculos afetivos é maior, pois é semelhante à forma de comportamento que uma pessoa mantém com alguém que é diferente e preferido. 13 A literatura afirma que os vínculos criados entre o enfermeiro e paciente torna-se ainda maior quando é em pediatria. Essa informação foi confirmada em alguns discursos dos participantes desta pesquisa. Alguns enfermeiros relatam que, quanto menor a criança, maior ainda se torna a ligação.

Eu já vivenciei mortes pediátricas, e, quanto menor a criança, maior a dor, porque eu sou apaixonada por bebês e, então, eu me apego muito mais aos bebês do que as crianças maiores, e é muito triste, quando a gente vê o paciente ir pra UTI, porque geralmente morre na UTI [...] Lidar com morte já é uma coisa difícil, principalmente pediátrica. (Rubi)

O vínculo é muito grande, muito, muito mesmo, é como se fosse da nossa família. Esse é um dos grandes dilemas da pediatria. Mulher principalmente, por que assim, eu não sou mãe, mas tenho sobrinhos, tenho afilhado, a gente acaba colocando aquela criança como se fosse nossa, quando é bebê então piora. (Ágata)

Todas as entrevistadas foram unânimes em suas respostas, quando questionadas sobre os vínculos afetivos criados entre o profissional e o paciente. Elas relataram que o vínculo existe, sim, e que é impossível não criá-los, visto que o paciente se torna uma parte da rotina delas. Em muitos relatos, fica evidente a representação de parentes por meio dessas crianças.

Eu já tive uma perda de uma paciente que eu tinha um vínculo muito forte e realmente é mais difícil, você passa um tempo pra se recuperar [...] Às vezes a relação é quase no nível de ser um parente nosso. (Esmeralda)

Nossa, eu crio vínculos eternos, muito mesmo, chego a ver como um ente querido. Principalmente por que a convivência aqui na oncologia é em longo prazo, a gente dá a alta ao paciente hoje sabendo que ele vai voltar amanhã [...] a convivência é muito grande, então é impossível não criar um elo, tanto com o paciente quanto com a família. (Safira)

A gente se apega muito ao paciente, a gente fica muito próxima dele, então, por exemplo, tem seis meses que eu vivenciei o óbito daquele paciente e hoje, eu ainda lembro, entende? Você realmente se apega, não tem como você esquecer, às vezes você leva para o resto da vida, como se fosse um parente mesmo. (Jade)

[...] você chega ao trabalho todo dia e vê, não tem como não criar um laço. Tem algumas crianças que se foram, que até hoje eu tenho fotos, por que a gente se apaixona mesmo. É diferente, a gente se compromete com eles [...] é da família mesmo. (Ametista)

Os longos períodos de internação hospitalar, o acompanhamento diário e o tratamento tornam o convívio mais próximo entre o enfermeiro e a criança inevitável. Os retornos rotineiros à unidade promovem um vínculo afetivo mais próximo com a criança e sua família, por meio da partilha de experiências boas e ruins vividas em face da patologia. 13 Relacionando os achados com a literatura, mais uma vez as informações são confirmadas. Alguns autores explicam que esse vínculo tão forte da enfermagem com o paciente pode estar relacionado com o convívio extenso e rotineiro.

Dessa maneira, fica evidenciado que os enfermeiros, inevitavelmente, criam vínculos afetivos com seus pacientes e que essa situação é ainda mais agravante na pediatria. Sendo assim, a facilidade de sofrer impactos em razão do óbito dessas crianças é ainda maior, pois, em muitos casos, o sofrimento assemelha-se à perda de um ente querido ou à solidariedade e transferência da dor de uma mãe para essas enfermeiras. Por esse motivo, foram investigadas, também, as estratégias que esses profissionais utilizam para minimizar os possíveis impactos em face do processo de morte do paciente pediátrico.

\section{As estratégias utilizadas pelos enfermeiros para superar esses impactos}

Os enfermeiros são submetidos a um misto de sentimentos durante a sua jornada de trabalho no ambiente hospitalar. Com base nos discursos coletados, ficou evidente que esses sentimentos causam impactos nesses profissionais e que, em longo prazo, podem causar danos a esse indivíduo. Dessa maneira, esses enfermeiros são obrigados a criar estratégias que minimizem a dor ou que impeçam a interferência dela na sua qualidade de vida.

Tento não ficar lembrando, não ficar pensando nisso [...] procuro fazer estratégias que proporcionem melhorar a qualidade de vida dele até o momento da morte e ter essa certeza que o ajudei. (Rubi)

Quando você entra, já vai criando meio que um mecanismo de defesa, porque você já sabe que você vai sofrer. Não estou dizendo que aqui a gente não sofre, mas a gente entende que temos que ter um enfrentamento, porque não é algo que vamos ver esporadicamente, nós vemos com muita frequência e, se a gente não entender que não pode absorver esse sofrimento, acabamos adoecendo e não conseguiremos trabalhar da maneira correta. (Esmeralda)

Se eu estiver vendo que a clínica do paciente está piorando, que ele pode vir a óbito, a gente, eu, pelo menos, começo a me distanciar, justamente para não ter esse sofrimento, entende? Minha estratégia é essa. (Turmalina)

Eu penso que cada um tem uma vida, não podemos perder a esperança; então, se eu não consegui com ele, posso conseguir com outro. Vou sempre continuar lutando pra que eu consiga dar uma assistência melhor, ver o que foi que errei, o que faltou e devolver aquela criança saudável para a família. (Jade)

Eu fico me policiando o tempo inteiro. Quando eu saio daqui, eu penso "preciso não levar isso pra minha casa", mas, às vezes, eu ligo, "e ai como tá ele?", mas a gente tenta ao máximo, me distanciando no sentido de não levar os problemas do trabalho pra casa, eu tento fazer dessa forma [...] (Opala)

Hoje eu tento ver que tudo que eu estou fazendo é para o bem daquela criança, estou buscando a melhora dela, mas não posso me culpar, caso ela venha a óbito. Eu tento separar os pensamentos para que isso não impacte na minha vida. (Ametista) 
Quando questionadas em relação a essas estratégias utilizadas, as enfermeiras entrevistadas demonstraram, em seus discursos, a tentativa de desvincular os fatos ocorridos no trabalho de sua vida pessoal, porém essa tentativa é feita sem nenhum tipo de apoio psicológico, o que se torna preocupante, pois, sem esse acompanhamento, elas não possuem uma real dimensão dos danos que esses impactos podem acarretar à sua saúde psíquica.

Acompanhar o processo de morte pediátrico provoca sentimentos negativos, como derrota, desapontamento, frustração, tristeza, luto, cobrança, quanto aos cuidados prestados, e pena. Por isso, é preciso observar, de maneira mais efetiva, as implicações que esses impactos do luto mal vivido podem gerar na vida desses profissionais, pois os sintomas não são vistos como doença, até o momento em que passam a interferir na rotina desses indivíduos, causando déficit em suas atividades e sofrimento intenso. Quando isso acontecer, é preciso que o enfermeiro saiba reconhecer e buscar ajuda adequada para lidar com essa situação ${ }^{13}$.

O luto não vivido e os impactos sofridos pelos profissionais de enfermagem estão relacionados. Por esse motivo, é necessário que haja uma atenção maior voltada para esses trabalhadores, pois as vivências desgastantes e pouco prazerosas no ambiente de trabalho podem desencadear a instalação de doenças, como a Síndrome de Bournot, termo novo, utilizado para explicar o sofrimento e o desgaste do profissional com as atividades desenvolvidas no trabalho ${ }^{13}$.

A literatura confirma que esses impactos têm relação significativa com o acometimento de patologias em enfermeiros que vivenciam processos de morte. Em apenas um relato, verificamos o apoio psicológico ofertado por meio de uma instituição, e ficou clara a sua importância para a enfermeira entrevistada e para a garantia da sua qualidade de vida e assistência.

Nas instituições que eu trabalhei [...], eles sempre faziam com a gente trabalhos voltados para a psicologia, cuidando de quem cuida. Lá a gente falava do processo de morte e morrer, a aceitação, a equipe perante a morte, eles sempre trabalharam muito em cima disso pra que os profissionais pudessem mudar sua visão sobre a morte [...] Por que assim, na graduação a gente não é preparada pra isso [...] a gente não é formado para lidar com a morte, a faculdade ensina que a enfermagem vai ser aquela que vai trazer o paciente sempre saudável. (Ágata)

Essa problemática é ainda mais grave ao concluir-se que as instituições hospitalares prestam pouco ou quase nenhum suporte psicológico para auxiliar esses profissionais a vivenciarem a morte de maneira menos impactante, o que pode acarretar danos graves à saúde mental da equipe de enfermagem ${ }^{14}$
Desse modo, analisando os relatos das entrevistadas, pode-se notar que as enfermeiras possuem dificuldades emocionais em trabalhar com pacientes pediátricos em processo de morte e que estão vivendo todo esse sofrimento sozinhas. É necessário que as instituições hospitalares tenham um olhar diferenciado sob essa ótica, visando ao benefício mútuo.

Não se podem ignorar as dificuldades enfrentadas pelo trabalhador, não só individual, como também coletivamente, os sentimentos vividos, os vínculos pessoais e interpessoais, a insatisfação e a necessidade de apoio. Assim, o profissional precisa ser visto como sujeito prioritário, uma vez que a história pessoal e social de cada um deve ser respeitada ${ }^{15}$.

Além disso, verifica-se que esses profissionais possuem um déficit em sua formação, pois esta, por muitas vezes, é mecanizada e voltada somente para o cuidar com ações técnicas e práticas, esquecendo que quem está à frente de todo esse cuidado são seres humanos, suscetíveis à formação de vínculos e aos sentimentos negativos.

As opções de melhora devem estar voltadas para as academias de formação profissional. É preciso preparar seus estudantes para entender o óbito como uma etapa do ciclo da vida e compreender o seu luto como uma resposta natural e necessária em face da perda de um paciente sob seus cuidados ${ }^{13}$.

\section{CONCLUSÃO}

O enfrentamento da morte é uma questão extremamente complicada e, quando ocorre na idade pediátrica, é ainda mais agravante e, por isso, precisa ser abordada com muito cuidado. Os relatos dos enfermeiros entrevistados nesta pesquisa demonstraram que, embora seja um evento rotineiro, ainda causa bastante sofrimento sempre que ocorre.

Constatou-se que, das enfermeiras entrevistadas, $100 \%$ sofrem com sentimentos negativos ao deparar-se com um óbito infantil. Sendo assim, fica claro que esses profissionais estão sendo expostos a esses impactos frequentemente nas unidades em que atuam.

Diante do que foi exposto nos relatos emocionantes das entrevistadas, torna-se evidente a criação de laços afetivos entre o enfermeiro e o paciente pediátrico e o fato de que essa relação é fortalecida quando a internação hospitalar é longa.

Baseado nos discursos obtidos, nota-se, ainda mais, que a vivência com o óbito de seus pacientes pediátricos causa impactos negativos nessas enfermeiras, mesmo que elas possuam anos de atuação na área, e que tem influência significativa em sua qualidade de vida, porém sem interferir na assistência prestada a outros pacientes.

\section{REFERÊNCIAS}

1. Oliveira SG, Quintana AM, Bertolino KCO. Reflexões acerca da morte: um desafio para a enfermagem. Rev. Bras. Enferm. [Internet]. 2010 [acesso: 2017 Abr 04]; 63(6): 1077-1080. Disponível em: http://www.scielo.br/pdf/reben/ v63n6/33.pdf. doi: http://dx.doi.org/10.1590/\$0034-71672010000600033.

2. Estatuto da Criança e do Adolescente. 9ạ edição. 2012. Brasília. 
3. Santos YS, Jesus LC, Portella SDC. A Enfermagem e a abordagem da morte infantil: Um estudo de trabalho qualis A. Rev. Enferm. Cont. 2013 Ago; 2(1): 112131. doi: http://dx.doi.org/10.17267/2317-3378rec.v2i1.252.

4. Mota MS, Gomes GC, Coelho MF, Sousa LD. Reações e sentimentos de profissionais da enfermagem frente à morte dos pacientes sob seus cuidados. Rev. Gaúcha Enferm. [Internet]. 2011 Mar [acesso em: 2007 Abr 4]; 32(1): 129-133. Disponível em: http://www.scielo.br/scielo.php?script=sci arttext\&pid=S1983-14472011000100017. doi: http://dx.doi.org/10.1590/ S1983-14472011000100017.

5. Ramalho MAN, Martins MCFN. Vivências de profissionais de saúde da área de oncologia pediátrica. Psicol. estud. [Internet]. 2007 Abr [acesso 2017 Abr 5]; 12(1): 123-132. Disponível em: http://www.scielo.br/scielo.php?pid=S141373722007000100015\&script=sci_abstract\&tlng=pt. doi: http://dx.doi. org/10.1590/S1413-73722007000100015.

6. Silva AM, Silva MJP. A preparação do graduando de enfermagem para abordar o tema morte e doação de órgãos. Rev. Enferm. UERJ. [Internet]. 2007 Out-Dez [acesso 2017 Abr 27]; 15(4): 549-554. Disponível em: http://www.facenf.uerj. br/v15n4/v15n4a12.pdf.

7. D’assumpção EA. Comportar-se fazendo bioética: para quem se interessa pela ética. Rio de Janeiro: Vozes; 1998.

8. Haddad DRS. A morte e o processo de morrer de crianças em terapia intensiva pediátrica: Vivência do enfermeiro [dissertação] [Internet]. Belo Horizonte (MG): UFMG; 2006 [acesso 2017 Abr 28]. Disponível em: http:// www.bibliotecadigital.ufmg.br/dspace/bitstream/handle/1843/GCPA-6VZQAP/ daniele_haddad.pdf?sequence=1.

9. Peixoto, MZMA. As emoções dos enfermeiros face à criança em fim de vida. [dissertação] Fac. de Med. da Universidade do Porto. [online]. 2014 [acesso em: 28/04/2017]. Disponível em: https://sigarra.up.pt/fmup/pt/pub_geral.show_ file?pi_doc_id=30205.

10. Reis TLR, Paula CC, Potrich T, Padoin SMM, Bia A, Mutti CF, et al. Relações estabelecidas pelos profissionais de enfermagem no cuidado às crianças com doença oncológica avançada. Aquichan. 2014 Dez; 14(4): 496-508. doi: 10.5294/aqui.2014.14.4.5.

11. Salomé GM, Cavali A, Espósito VHC. Sala de Emergência: o cotidiano das vivências com a morte e o morrer pelos profissionais de saúde. Rev. Bras. Enferm. [Internet]. 2009 [acesso 2017 Maio 01]; 62(5): 681-686. Disponível em: http:// www.scielo.br/scielo.php?script=sci_arttext\&pid=S0034-71672009000500005.

12. Machado WCA, Leite JL. Eros e Thanatos: a morte sob a óptica da enfermagem. 2.ed. São Caetano do Sul: Yends; 2006.

13. Costa JC, Lima RAG. Luto da equipe: revelações dos profissionais de enfermagem sobre o cuidado à criança/ adolescente no processo de morte e morrer. Rev. Latino-am Enf. [Internet]. 2005 Mar-Abr [acesso 2017 Maio 1]; 13(2): 151-157. Disponível em: http://www.scielo.br/scielo.php?script=sci_ arttext\&pid=S0104-11692005000200004.

14. Marques CDCM, Veronez M, Sanches MR, Higarashi IH. Meanings assigned by a pediatric intensive care unit nursing team on the processes of death and dying. Rev. Min Enferm. [Internet]. 2013 Oct-Dec [acesso 2017 Maio 1]; 17(4): 831-837. Disponível em: http://www.reme.org.br/artigo/detalhes/889.

15. Rockembach JV, Casarin ST, Siqueira HCH. Morte pediátrica no cotidiano de trabalho do enfermeiro: Sentimentos e estratégias de enfrentamento. Rev. Rene. Fortaleza. [Internet]. 2010 Abr-Jun [2017 Maio 1]; 11(2): 63-71. Disponível em: http://www.revistarene.ufc.br/vol11n2_pdf/a07v11n2.pdf.

\section{Como citar este artigo/How to cite this article:}

Souza FF, Reis FP. 0 enfermeiro em face ao processo de morte do paciente pediátrico. J Health Biol Sci. 2019 Jul-Set. 7(3):277-283. 